\title{
EDUCAÇÃO AMBIENTAL NA SOCIEDADE DE RISCO
}

\author{
Cristiane Angélica de Paiva Paula
}

Universidade Tecnológica Federal do Paraná, Programa de Formação de Professores, Londrina, PR. E-mail: cristianedireito@hotmail.com

\section{RESUMO}

A modernidade convive com os riscos de ocorrência de catástrofes ambientais amplas que colocam em dúvidas a continuidade da espécie humana. A crise ambiental não se restringe ao meio ambiente natural, mas é social e de valores, que possui cunho eminentemente político. Por isso, o objetivo deste estudo foi analisar a mudança de paradigmas que envolve a educação ambiental (EA) em meio a sociedade de risco. A metodologia constou de estudo qualitativo, com foco na pesquisa bibliográfica e descritiva. Os resultados mostraram que há uma contraposição entre EA conservadora e crítica. E assim, conclui-se que a EA crítica fornece maiores subsídios para a construção de uma sociedade que seja efetivamente sustentável.

Palavras-chave: Currículo. Educação Ambiental Crítica. Professor. Processos de Ensino-Aprendizagem. Aluno.

\section{ENVIRONMENTAL EDUCATION IN RISK SOCIETY}

\begin{abstract}
Modernity coexists with the risks of large environmental disasters that put in doubt the continuity of the human species. The environmental crisis is not restricted to the natural environment, but is social and values, which has an eminently political seal. Therefore, the aim of this study was to analyze the paradigm change that involves environmental education (EE) in the risk society. The methodology consisted of a qualitative study, focusing on literature and descriptive. The results showed that there is a contrast between conservative and critical EE. And so it follows that critical EE provides higher subsidies for the construction of a society that is really sustainable.
\end{abstract}

Keywords: Curriculum. Critic Environmental Education. Professor. Teaching and learning process. Student.

\section{INTRODUÇÃO}

Atualmente, a sociedade convive com diversos problemas ambientais associados à ação predatória do homem na natureza. Ao lado de problemas perceptíveis, típicos da sociedade industrial, o homem passa a conviver com os riscos amplos e invisíveis. Somente uma modificação do agir ético será capaz de alterar previsões acerca do futuro catastrófico que espera a humanidade. $\mathrm{E}$ esta mudança está diretamente relacionada à relação homem- meio ambiente e ao tipo de educação capaz de garantir a criação de um sujeito ecológico.

Portanto, o objetivo deste artigo foi analisar a educação ambiental (EA) sob uma pespectiva crítica, discutindo os papéis das instituições de ensino para a concretização de um desenvolvimento que seja efetivamente sustentável, tendo por base a Teoria da Sociedade de Risco proposta por Ulrich Beck, justamente pela sua proximidade com a temática ambiental.

\section{METODOLOGIA}

O presente estudo será baseado em estudo qualitativo, com foco na pesquisa bibliográfica e descritiva. Através do método dialético busca-se analisar as nuâncias nos processos de ensino e aprendizagem e a definição de atitudes ambientalmente corretas.

\section{RESULTADOS}

Os resultados demonstraram que as concepções acerca do homem e da relação homem-natureza vão definir os rumos da sociedade atual: se prossegue com a ação predatória e assume o risco de extinguir, mais cedo ou mais tarde, a vida humana ou se modifica ideologicamente as bases do problema para 
alterar a relação homem e natureza, reconhecendo que entre estas há uma simbiose.

Neste sentido, a EA sob o viés crítico ou conservador demonstra claramente uma diferença de ideologia e isto vai influenciar nos processos de ensino e aprendizagem. Ou a sociedade assume uma postura passiva e a educação se fixa como uma forma de manutenção do sistema de dominação ou busca-se, sob uma perspectiva crítica, um atuar conjunto na construção do conhecimento, pautando-se na garantia dos direitos sociais e políticos.

\section{DISCUSSÃO}

\section{Sociedade de Risco}

A relação ética entre o homem e a natureza definiram historicamente os rumos da sociedade. Com Descartes, no século XVII, a "objetividade cartesiana fez com que "perdêssemos" a possibilidade de pensar historicamente e colocou o homem europeu e branco na posição de Dono e Senhor da natureza" (GRUN, 2009, p. 63). A natureza tinha um sentido utilitário, despida de valor, prevalecendo a ideia de que a natureza era apenas fonte recursos materiais e, por isso, era possível dominá-la. Esta concepção ficou conhecida como "antropocentrismo".

Principalmente a partir da Revolução Industrial, o homem começou a utilizar tecnologias com vistas ao aumento da produtividade e maximização de lucros, o que fez com que a destruição ambiental fosse intensificada.

A visão antropocêntrica e utilitarista que permeava a relação homem-meio ambiente perdurou por muitos anos e ainda prevalece em diversos discursos atuais. Contudo, esta visão está se modificando paulatinamente, o que começou a ocorrer, sobretudo, com a publicação do livro "Primavera Silenciosa", de Rachel Carson (2010), no qual foram denunciados os riscos à saúde humana e à natureza advindos do uso desregrado de produtos químicos na agricultura. Ou seja, constatou-se que os danos ambientais são frutos da ação humana.

Assim, a natureza responde às agressões humanas de maneira que os homens passam a sofrer as consequências de suas póprias ações. Esta constatação vai modificar a forma de pensar, sob o ponto de vista de uma relação de complementaridade, oque está bastante relacionada ao que o filósofo Espinosa defendia já no século XVII, uma ética da totalidade, na qual "ao maltratar o mundo, você está maltratando a si mesmo" (SAWAIA, 2009, p. 81). E nesta ideia, há uma sensação de pertencimento do ser humano no meio natural.

Em 1972, ocorreu a Primeira Conferência da Organização das Nações Unidas sobre o Meio Ambiente Humano, em Estocolmo que reconheceu que "por ignorância ou indiferença, podemos causar danos imensos e irreparáveis ao meio ambiente da terra do qual dependem nossa vida e nosso bem-estar" (ONU, 1972). Esta Conferência significou um marco em relação à conscientização em nível internacional acerca dos problemas ambientais e da necessidade de uma atuação conjunta de todos os países na busca por soluções.

Em 1986, Ulrich Beck publicou seu livro "Risk Society: towards a new modernity", no qual o autor relata a transição da sociedade industrial para a sociedade de risco (BECK, 2010). A sociedade de risco "designa um estágio da modernidade em que começam a tomar corpo as ameaças produzidas até então no caminho da sociedade industrial" (BECK, 1987, p. 17). Segundo o renomado sociólogo alemão, a modernidade convive com os riscos de ocorrência de catástrofes ambientais. Os riscos deixam de ser geograficamente delimitados, se prolongam no tempo, são incertos e imprevisíveis. Em outras palavras, as tecnologias que prometiam a melhoria da qualidade de vida e a felicidade de todos no período da Revolução industrial trouxe a reboque riscos de amplitudes inimagináveis e que colocam em dúvidas a continuidade da vida no planeta.

Neste contexto, Beck (2010) menciona que há uma ruptura das instituições tradicionais que não conseguem mais dar respostas plausíveis para a crise da modernidade. Assim, a ciência não é capaz de prover soluções para os riscos e, assim, a sociedade vive em meio a incertezas.

Toda esta problemática ambiental faz surgir uma nova forma de pensar o Estado e o desenvolvimento, com base na sustentabilidade. Esta possui um conceito multidimensional, buscando compatibilizar questões sociais, ambientais, econômicas, políticas e territoriais (SACHS, 2008).

Para Jacobi (2005, p. 238) a ideia de sustentabilidade propugna que é preciso "um conjunto de iniciativas que levem em conta a existência de interlocutores e participantes sociais relevantes e ativos por meio de práticas educativas e de um processo de diálogo informado, o que reforça um sentimento de co-responsabilização e de constituição de valores éticos". Deste modo, tanto o poder público quanto a própria sociedade são corresponsáveis pela concretização de um desenvolvimento sustentável. 
Justamente por estar os problemas ambientais relacionados ao modo de vida do homem, o problema da crise ambiental também é um problema social, uma vez que há incompatibilidade entre 0 desenvolvimento sustentável e os princípios basilares do capitalismo (FOLADORI, 2001). Portanto, é preciso mais do que ações paliativas, mas sim é necessário uma mudanças no "Ser" do próprio homem, alterações dos valores.

Da mesma forma, as incertezas demonstram que há claramente uma crise no saber, que demanda uma visão holítica e interdisciplinar, já que a ciência é dominadora e torna a sociedade alienada, por isso há um desconhecimento generalizado (LEFF, 2011).

Por outro lado, a crise sistêmica traz consigo uma nova categoria de direitos fundamentais e impõe ao Estado de Direito a reformulação de seus pilares e a busca por novas alternativas (FERREIRA; LEITE, 2012). O Estado passa a ter como objetivos, dentre outros, a busca por uma conscientização coletiva ambiental e a institucionalização de mecanismos compatíveis com a natureza dos problemas ambientais com foco na gestão de riscos (FERREIRA; LEITE, 2012). Em outras palavras, o Estado deixa de ser mero expectador e passa a atuar ativamente na busca da sustentabilidade, por meio de projetos políticos sustentáveis.

E quando falamos em conscientização ambiental é crucial discutir o papel da educação como forma de buscar soluções, garantir a democratização e ampliação do acesso a informação capaz de propiciar uma atuação coletiva para implementar a sustentabilidade. Contudo, não há que se olvidar que nos defrontamos com o quetionamento sobre qual tipo de educação é hábil a enfrentar os problemas da modernidade, bem como os papéis que os professores possuem na criação de um sujeito ecológico.

\section{Educação ambiental e crítica}

A EA surge permeada pelas contradições acerca do lugar onde o homem se enquadra no contexto ambiental. Tradicionalmente, a visão antropocêntrica dominou as relações e o pensamento, inclusive os processos de ensino e aprendizagem. No entanto, é preciso afirmar uma visão socioambiental, que "exige um esforço para a superação da dicotomia entre natureza e sociedade, para poder ver as relações de interação permanente entre a vida humana social e a vida biológica da natureza" (CARVALHO, 2012, p. 37). E a educação deve se adequar a esta forma de abordagem para criar um sistema cíclico, no qual homem e meio ambiente estão em sintonia.

A Conferência Intergovernamental de Educação Ambiental ocorrida em 1977, em Tbilisi, é um marco significativo na história da EA. Esta Conferência estabelece como objetivos a compreensão da realidade do meio ambiente natural e artificial pela coletividade e o "incentivo à aquisição de conhecimentos, valores, comportamentos e habilidades práticas para participar da prevenção e da solução da gestão ambiental" (DIAS, 2003). Assim, a EA deve estar atrelada à realidade fática, ou seja, os indivíduos devem ser orientados para a solução de problemas reais.

Já na Rio-92, Conferência das Nações Unidas sobre o Meio Ambiente e o Desenvolvimento, ocorrida no Rio de Janeiro em 1992, representou um grande avanço neste ramo, já que redigiu 0

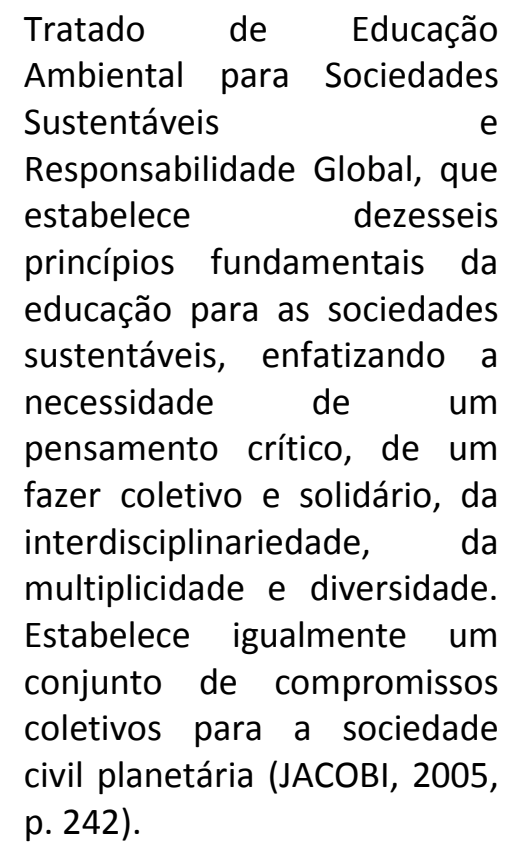

Capra (2006) vai defender justamente a necessidade de ter um pensamento sistêmico, tão difícil de se conseguir face a cultura materialista dominante. $O$ pensamento linear, típico da educação tradicional, que dispõe sobre cadeias de causa e efeito, não é suficiente para criar uma sociedade sustentável. Então, é preciso criar uma nova forma de ver e pensar o mundo, com base nas relações, conexões e contexto.

No Brasil, para garantir a efetividade do direito ao meio ambiente ecologicamente equilibrado, o artigo 225, $\$ 1$ o, inciso $\mathrm{VI}$, da Constituição Federal determina que é dever do poder público "promover a educação ambiental em todos os níveis de ensino e a conscientização 
pública para a preservação do meio ambiente"(BRASIL. Constituição, 1988, p. )

A lei no 9.795/99 instituiu a Política Nacional de Educação Ambiental, dispondo em seu artigo 2으, que a EA é essencial e permanente na educação nacional e deve ser desenvolvida de forma integrada em todos os níveis de ensino formais e não formais, conforme prevê o art. 3‥ Vale ressaltar ainda que em seu artigo 11, a lei prevê que a "dimensão ambiental deve constar dos currículos de formação de professores, em todos os níveis e em todas as disciplinas" (BRASIL, 1999).

Mas o que é EA e como abordá-la? A Lei no 9.795/99 traz que a EA configura "os processos por meio dos quais o indivíduo e a coletividade constroem valores sociais, conhecimentos, habilidades, atitudes e competências voltadas para a conservação do meio ambiente" (BRASIL, 1999).

Todavia, Carvalho (2004, p. 16) relata a existência de múltiplas educações ambientais e a existência da própria adjetivação "ambiental" do termo "educação" destaca "uma dimensão, ênfase ou qualidade que, embora possa ser pertinente aos princípios gerais da educação, permanecia subsumida, diluída, invisibilizada, ou mesmo negada por outras narrativas ou versões predominantes". Assim, ela se legitima no momento em que há uma "aspiração legítima, sócio-historicamente situada, que sinaliza para o reconhecimento da importância de uma educação ambiental na formação dos sujeitos contemporâneos".

Diante de várias educações, Guimarães (2004) vai contrapor a noção de e EA conservadora e crítica. A conservadora, segundo o autor, não é instrumentalizada e não se preocupa com as transformações da realidade ambiental, ela visa reproduzir os instrumentos de dominação, se atendo ao cientificismo cartesiano e ao antropocentrismo. Ela visa o "aspecto cognitivo do processo pedagógico, acreditando que transmitindo o conhecimento correto fará com que $o$ indivíduo compreenda a problemática ambiental e que isso vá transformar o seu comportamento e a sociedade (...)". (GUIMARÃES, 2004 , p. 27). No entanto, a EA crítica subsidia uma leitura mais complexa e instrumentalizada de mundo, com vistas a transformação. Seria uma forma de sair do campo teórico para encampar a práxis.

E assim, esta formulação parte do pressuposto de que ensinar não é transferir conhecimento, mas sim criar possibilidades de sua produção e construção (FREIRE, 1997). E neste aspecto, deixa-se de dar um enfoque prioritário no professor e há um reconhecimento do papel do aluno na construção do saber.

Para Lima (2009) o ensino não é neutro ou destituído de valores e ideologias e, por isso pode reproduzir ou manter a ordem social. Segundo o autor, a EA conservadora esteve muito ligada às ciências naturais, pois foram os primeiros a denunciarem os problemas ambientais. Isto fragmentou a educação, no sentido de enfatizar o caráter ecológico dos danos ambientais, deixando de lado aspectos sociais, políticos, econômicos e culturais. No que se refere a conteúdo ministrado, é totalmente tecnicista, reduzindo o discurso a causa e efeito. Por isso, o foco é no indivíduo como agente da ação degradante e busca uma conscientização individualizada e informativa. Porém, na educação crítica esta características são problematizadas, pois o problema ambiental deixa de possuir apenas um cunho "ambiental" para abranger questões sociais e políticas, por isso dizse que a EA é um ato político. Muito influenciada pelo pensamento freiriano, entende-se a pedagogia como uma "construção social dialógica e coletiva, que persegue o pensamento crítico, a formação de sujeitos emancipados e a transformação da realidade sociocultural e política" (LIMA, 2009, p. 156).

Enfim, a partir de uma análise crítica da educação ambiental há uma modificação das próprias bases e paradigmas que envolvem os processos de ensino e aprendizagem.

\section{CONCLUSÃO}

Por todo o exposto, a Teoria da Sociedade de Risco nos confere subsídios teóricos para pensar na EA que não concentra suas atenções apenas em soluções paliativas ou informativas, mas sim que atua no cerne da própria origem da crise ambiental, que é a própria concepção de homem e as seus modos de vida.

A inserção da praxis no campo educacional é de suma importância para a criação do sujeito ecológico. O papel do professor na condução de atividades que visam garantir ao aluno o seu reconhecimento como cidadão e corresponsável pelo futuro da humanidade é um papel político e ideológico. $E$ nos processos de ensino e aprendizagem que seja crítico, tanto o professor quanto o aluno é quem criam o conhecimento e, juntos, trazem novas perspectivas para pensar uma solução real para os problemas, que não são apenas ambientais, mas sociais e políticos. 


\section{REFERÊNCIAS}

BECK, U. A reinvenção da política: rumo a uma teoria da modernização reflexiva. In: BECK, U.; GIDDENS, A.; LASH, S. Modernização reflexiva: política, tradição e estética na ordem social moderna. São Paulo: Ed. da Unesp, 1997.

Sociedade de Risco: rumo a uma outra modernidade. Tradução Sebastião Nascimento. São Paulo: Ed. 34, 2010. 384 p.

BRASIL. Constituição (1988). Constituição da República Federativa do Brasil. Brasília, DF: Senado Federal, 1988. 292 p.

BRASIL. Lei no 9.795, de 27 de abril de 1999. Dispõe sobre a educação ambiental, institui a Política Nacional de Educação Ambiental e dá outras providências. Diário Oficial, Brasília, DF, 28 de abr. de 1999. p. 1

CAPRA, F. Falando a Linguagem da natureza: Princípios da Sustentabilidade. In: STONE, M. K.; BARLOW, Z. Alfabetização ecológica: a educação das crianças para um mundo sustentável. São Paulo: Cultrix, 2006. p. 46-57.

CARSON, R. Primavera Silenciosa. São Paulo: Gaia, 2010.

CARVALHO, I. C. de M. Educação ambiental crítica: nomes e endereçamentos da educação. In: LAYRARGUES, P. P (org). Identidades da Educação Ambiental Brasileira. Brasília: Ministério do Meio Ambiente, 2004. p. 13-24.

Educação ambiental: a formação do sujeito ecológico. 6. ed. São Paulo: Cortez, 2012.

DIAS, S. M. F. Avaliação de projetos de educação ambiental voltados para o gerenciamento de resíduos sólidos urbanos. 2003. 326 f. Tese (Doutorado em Saúde Pública) - Universidade de São Paulo, São Paulo.

FERREIRA, H. S. ; LEITE, J. R. M. A expressão dos objetivos do Estado de direito ambiental na Constituição Federal de 1988. In: LEITE, J. R. M; FERREIRA, H. S; CAETANO, M. A (org.). Repensando o estado de direito ambiental. Florianópolis: Fundação Boiteux, 2012. v. 3, p. 1748.

FOLADORI, G. Limites do desenvolvimento sustentável. Campinas, SP: Ed. da Unicamp, 2001. FREIRE, P. Pedagogia da autonomia. 2. ed. Rio de Janeiro: Paz e Terra, 1997.

GRUN, M. Decartes, historicidade e educação ambiental. In: CARVALHO, I. C. M. ; GRUN, M. ; TRAJBER, R. (Org.). Pensar o ambiente: bases filosóficas para a Educação Ambiental. Brasília: Ministério da Educação, Secretaria da Educação Continuada, Alfabetização e Diversidade; UNESCO, 2009. p. 63-77.
GUIMARÃES, M. Educação ambiental crítica. In: In: LAYRARGUES, P. P (org). Identidades da educação ambiental brasileira. Brasília: Ministério do Meio Ambiente, 2004. p. 25-34.

JACOBI, P. R. Educação ambiental: o desafio da construção de um pensamento crítico, complexo e reflexivo. Educação e Pesquisa, São Paulo, v. 31, n. 2, p. 233-250, maio/ago. 2005.

ONU. Conferência das Nações Unidas sobre o Meio Ambiente Humano. 1972. Disponível em: < http://www.direitoshumanos.usp.br/index.php/M eio-Ambiente/declaracao-de-estocolmo-sobre-oambiente-humano.html>. Acesso em: 15 fev. 2016. LEFF, E. Complexidade, interdisciplinaridade e saber ambiental. Revista Olhar de Professor, Ponta Grossa, v. 14, n. 2, p. 309-335, 2011. https://doi.org/10.5212/OlharProfr.v.14i2.0007

LIMA, G. F. da C. Educação ambiental crítica: do socioambientalismo às sociedades sustentáveis. Educação e Pesquisa, São Paulo, v.35, n.1, p. 145163, jan./abr. 2009. https://doi.org/10.1590/S1517-

97022009000100010

SACHS, I. Desenvolvimento includente, sustentável sustentado. Rio de Janeiro: Garamond, 2008.

SAWAIA, B. B. Espinosa: o precursor da ética e da educação ambiental com base nas paixões humanas. In: CARVALHO, I. C. M. ; GRUN, M.; TRAJBER, R. (Org.). Pensar o ambiente: bases filosóficas para a Educação Ambiental. Brasília: Ministério da Educação, Secretaria da Educação Continuada, Alfabetização e Diversidade; UNESCO, 2009. p. 78-91.

Recebido para publicação em 26/08/2016

Revisado em 22/09/2016

Aceito em 28/09/2016 